\title{
Culture and Aesthetic Choice of Sports Dance Etiquette in the Cultural Perspective
}

\author{
Baodong Wang ${ }^{1}$ \\ ${ }^{1}$ PE Institute, Qingdao University of Science and Technology, China \\ Correspondence: Baodong Wang, PE Institute, Qingdao University of Science and Technology, China. E-mail: \\ 279759996@qq.com
}

Received: August 3, 2015 Accepted: October 26, 2015 Online Published: October 28, 2015

doi:10.5539/ass.v11n25p160 URL: http://dx.doi.org/10.5539/ass.v11n25p160

\begin{abstract}
Compared with other artistic expression, sports dance etiquette has a broader development space with its cultural and aesthetic characteristics as a carrier of culture and art. Moreover, Sports dance etiquette is a kind of respect and promotion between dancers, the dancers and the audiences, the dancers and the society. Furthermore, the diversity culture of sports dance gives it more marked symbols. Aesthetics and ritual performance of sports dance is the development road of society and art heritage. Based on this, this article researches on cultural and aesthetic characteristics of sports dance combing with the practice. All in all, it views to provide a useful reference to better promoting the research of sports dance etiquette.
\end{abstract}

Keywords: sports dance, dance etiquette, cultural characteristics, aesthetic characteristics

\section{Introduction}

Sports dance is a kind of comprehensive art projects of body language, dancing, the theme and emotional expression. Its elegant dance, dance moves and colorful dancing costumes, make sports dance with a cultural aesthetic characteristics and multiple ways of artistic practice. Sports dance etiquette is a kind of respect and promotion between dancers, the dancers and the audience, dancers and society, and also, the culture of sports dance etiquette makes the sports dance has more identifiers. Research on sports dance etiquette culture and aesthetic characteristics can help us better understand and recognize the value of expression power in sports dance performance.

\section{The Perspective of Culturology in Sports Dance Etiquette Culture and Aesthetic Attributes}

\subsection{Sports Dance Etiquette Aesthetic Is the Unity of These Two Attributes in Natural Beauty and Social Beauty}

From the aesthetics perspective of the etiquette of sports dance, sports dance doesn't belong to the real beauty. On one hand, aesthetics of the etiquette of sports dance has the basic characteristics of the natural beauty, On the other hand, it also has the basic characteristics of social beauty. As persons' sports dance, in the process of sports dance, individual sports dance is the main ways and means of the practical expression of sports dance. The nature of the body is a kind of natural beauty. As a result, human body with natural attribute unifies in together with social organic of sports dance. On the social nature of the individual, the investigation and accurate grasp of the human nature, is a better understanding of natural beauty and social unity of sports dance. The development of human beings is the result of a long-term individual adaptation to natural selection. In the long course of history, the human beings become attractive group. Physical beauty is a basic category of the social beauty with social attributes. In the realm of social beauty, the aesthetic of sports dance etiquette is based on the human body beauty, engaging in all kinds of suitable practice activity and human development. In the process of human practice, the natural form and social form gradually develop in the unified direction. Human's understanding of aesthetics of sports dance etiquette changes from the original single body beauty toward a higher level of development of social beauty, spiritual beauty. All these constantly enrichment and improvement make further expansion of the value function of aesthetic of sports dance etiquette. In the realm of aesthetics of sports dance etiquette, it is a fusion process between human and itself, human and nature, human and society with competition, but not just stimulus and experience of the sports dance.

\subsection{Sports Dance Etiquette Aesthetic Is the Double Performance of Masculine and Feminine Beauty}

The human being is composed of millions of individual life. First of all, we analyze from the perspective of the 
human physique, the evolution of the human body structure and skills are from lower toward advanced. Secondly, from simple evolution toward complex process, in the course of these changes in humans, it achieved the two-way development of bio-based and natural attributes. The human being is a result of natural selection, its natural attributes showing the beauty of structure that belong to the human-specific. For example, coordination and symmetrical shape for human body, structure characteristics. Gender differences brought significant influence in the physical structure of men and women to the body and shape, men show as masculine, muscular, physically robust. While women are more feminine beauty, women's body is more rounded, beautiful. With the help of the practice of sports dance expression, the differences of men and women showed a greater charm. These charms can fully demonstrate and continue to improve the man's masculine, feminine beauty. Of course, with the development of modern sports, a growing number of sports dance project began demanding female sports dancers to have good muscle strength, and in the chic appearance and rhythmic movements, women sports dance also showed a masculine beauty, feminine beauty features. But whether it is competitive sports dance or daily fitness, individual men and women exhibited a masculine and feminine beauty is the eternal theme for sport dance ritual aesthetics.

\subsection{Sports Dance Etiquette Aesthetic Is the Combination of Inside and Outside between Formal Beauty and Physical Beauty}

Sports dance as an individual and group planned to achieve physical and psychological health. The healthy body and mind developed in this process has an important role in personal characteristics promoting. Thus, in terms of fitness or viewing angle, sports dance is a practical form of aesthetic activity. For generalized, sport dance is formulated in the process of human development, in order to get a better survival and production, on the basis of the human body and mind law of development, through physical exercise as a basic means to get healthy body and mind Practice. Under modern society view, sports dance etiquette aesthetics category has been expanded, sports dance sport as a basic tool in the process of expanding its feature richness and uniqueness, and this is also the proof for understanding and the pursuit of sports dance etiquette aesthetic. In the river of history, sports and education has a close relationship, sports in not only the basis of an educational activity, but also the basic necessary elements for educational practice. The development of education brings sports more opportunities and space, and it makes a constitution of the moral, intellectual, an aesthetic education. In the course of sports dance development, the diversity of form and the form of enthusiasm make sports dance etiquette aesthetic have a positive influence to the development of dedicatee's physical and mental health. The content of sports dance is a starting point in the school's educational goals and it is constantly enriched and improved. Sports dance education and Military Education have a close relationship, and it is these real sports dance aesthetic etiquette that make us feel the pleasure of sports dance and positive experience. Sports dance is one of the sports dance forms of social and cultural phenomenon, in the process of sports dance both the diversity of forms of expression of beauty have all a distinctive trait of sports dance again. All in all, Sports dance etiquette aesthetic field is an integrated embodiment of the physical, psychological, cultural and human spirit.

\subsection{Sports Dance Etiquette Is the Combination of the Skills Beauty and Style Beauty}

In the category of aesthetics, sports dance sport dance techniques and styles is the essence of sports dance etiquette and aesthetic expression. Skills and styles including the following three aspects: Firstly, individual recognize and use the knowledge of the objective laws. Secondly, Individuals by its inevitable progress towards late free process. Thirdly, after the performance of personality traits gradually adept skill to master and sublimation, that is the overall unity of sports dance content and individual character of the process. Sports dance skills can reflect the individual comprehensive beauty, and this beauty is integrated through sport dancing skills to express, every dance sport dancers, dance sports law can only be achieved with physical and mental characteristics in the best status, when to be able to show a unique charm. Therefore, the sport dance became another major character and expression of the technique dance etiquette and aesthetics. The continuous development of science and technology brought unprecedented progress in enhancing the sports dance skills. Meanwhile, More Various training methods and equipment in line with human sports dance law in promoting sports scores and improve sports dance skill, and it brings unlimited possibilities in sports dance ceremonial aesthetic sublimation and further creation. It is under the background of in a rapidly changing sports dance style and dance skills that sports dance ritual aesthetics has been constantly improved and enriched. What's more, the new sports dance ritual aesthetics constantly update people's understanding and awareness in aesthetic sports dance etiquette. 


\section{The External Performance and Characteristics of Sports Dance Etiquette Culture}

\subsection{First of Sports Dance Etiquette Characteristics: Rigorous Sports Dance Etiquette Procedures}

In the process of sports dance practice and display, strict and standard of sports dance etiquette becomes one of the main content of the sports dance aesthetic, these dance etiquette are the external display of sports dance culture. Sports dance etiquette includes the dancer to the audience's respect, mutual respect, respect for the referee, and respect for the dance culture and so on. Dance performer by completing the dance movements, dance etiquette procedures, to achieve the expression of dance and the reshaping of the emotional theme and innovation. For example, after completed regulations dance moves, the dancers say hello to salute the audience. In the process of sports dance performance, according to the characteristics of different types of dance to formulate the different sports dance etiquette, and in the process of sports dance competition, the quality of sport dance etiquette completion also makes a big effect to the contestants' performance.

\subsection{Second of Sports Dance Etiquette Characteristics: Elegant Sports Dance Demeanor}

Sports dance as a graceful movement project, both have the men virile beauty and women represent the soft beauty. Therefore, in the process of sports dance performances, the combination of dance sport aesthetics and sports dance etiquette makes the sport have a big potential to develop. In actual sports dance performances, the dance demeanor characterized as elegant at the same time. Compared with the exciting bold folk dance, sports dance performance is more fluent and unrestrained. In etiquette culture, the grace of sports dance is the main connotation of sports culture characteristics. Therefore, in the process of sports dance performance and research, it needs sport dancers double expression of artistic image and temperament to reflect the cultural connotation of sports dance. Also, In the process of sports dance performances, no matter what type of dance and no matter what dance steps that the dancers are dancing, the dancers can't disorderly dance routine. The dancers should need to perform in accordance with the center of the dance floor counterclockwise, and they can't on the rampage random. In the process of performing, if the dancers collisions with other dancers accidentally, they need to apologize to them initiative. Because of the development of sports dance etiquette culture to promote the development of dance shows more sustainable, Grace of sports dance etiquette manners has become a necessary way of scoring.

\subsection{Third of Sports Dance Etiquette Characteristics: Noble Sports Dance Artistic Accomplishment}

Dance sport as a way of practice of cultural performance, sports dance can show etiquette culture advocated by the personal accomplishment and etiquette. In many western movies, the hero always tends to invite dancers polite, which makes a deep expression to audiences. And in the behind of this phenomenon, it is a noble quality sports dance culture. Early in the development of sports dance, before the men and women both parties dance, it needs to go through a set of complex invite and accept movements, which also demonstrates the feasibility of sports dance etiquette culture and promotes sports dance aesthetic. Although it has experienced year's evolution and development, the tedious sports dance etiquette becomes more concise, but it still consolidates its etiquette culture, which belongs to the original sports dance and moved. And these are also the vitality for sports dance civilized manners and the sustainable development of sports dance.

\subsection{Fourth of Sports Dance Etiquette Characteristics: Fusion for Variety Dance of National Culture}

Dance sport as a way of practice of different regional culture, it is also an important carrier of cultural inheritance. In the process of continuous development in the sports dance, dance sport becomes the fusion and development of the national culture and etiquette culture. In this process, as a form of aesthetic and dance movement performance, sports dance is in organic fusion and change gradually. For example, in the process of the development of modern dance of the waltz dance, it constantly absorbs the artistic style and performance of Latin dance, which makes modern waltz more concise, open and dynamic. Just like other artistic expression, the progress and development of sports dance are based on sports dance culture. Therefore, under the background of accelerating globalization and cultural exchange, the mutual fusion of sports dance etiquette cultures makes sports dance in a more close, nature way in attracting more and more dance lovers to join in. And in the process of the integration and development of sports dance, it is in a unique way to show different etiquette characteristics and connotation of national culture, which make the sports etiquette culture and aesthetic characteristics of dance in a more space and endurance to develop.

\section{The Motion Process of Sports Dance Etiquette and Aesthetic Choice}

\subsection{The Beauty of Sports Dance Etiquette Emotion}

First of all, Sports dance as a physical sign language to communicate, it convey information and express feelings through dance. Secondly, as a sport beauty, emotional beauty of artistic expression, it can be accessed to be a 
more real emotional experience in a wonderful dance and melody. The beauty of sports dance emotion can be performed: sports dance theme of the sublime, sports dance dignified deportment, sports dance exhibit of freedom, and the expression of emotions of sport dance. Moreover, sports dancers with professional dance artistic expression, body language, dance, sports dance to express emotions. Meanwhile, as a driving force of artistic expression, every sports dance performing express their inner feelings and understanding for all sport dancers. Therefore, sports dance language becomes one closest way in expression emotions.

\subsection{The Beauty of Sports Dance Etiquette Moral}

In the process of the development of sports dance, it needs a sports dance performers dance movements, dance expression, personal temperament to show the moral beauty of dance. Sports dance is a kind of single, double and more the project, in the process of performance, the dancer unity, cooperation and responsibility become the external display for sports dance moral beauty. In the process of ascension of sports dance performance, the effective cooperation, care and love between partners, and sense of responsibility for the audience, which will make the audience in more deeply realization of the moral beauty of sports dance. Sports dance of moral beauty can bring spiritual shock and stimulation to the audience, at the same time, when the audience in enjoying the beauty of sports dance moves, they can obtain the inner positive experiences and feelings.

\subsection{The Beauty of the Rhythm of Sports Dance Etiquette}

Sports Dance rhythm as temporal changes in the structure of both sports, whether it is fast-paced sports or soothing rhythms of dance, it will more exciting and wonderful because of the sport dance rhythm. In the course of sports dance, the beauty of rhythm should performed the rhythm for the condition, under the accompaniment of music, it performs regular and repetition expression, Rhythm beauty reflects flow of movement of sports dance rhythm and music melody system of aesthetic feeling. In sports dance music rhythm, the rhythm is the basic law, a change of pace to make dancers feelings, dances and others to change. The rhythm of the diversity made the expressive force of sports dance more prominent. At the same time, Sports dance rhythm beauty let sports dance practitioners of the dance rhythm and melody changes are more advantageous to dance performance of the emotion. In the realization of dance music beauty and organic integration the creation of unlimited support for sports dance art emotion expression of the theme.

\subsection{The Beauty of Sports Dance Etiquette Dress}

Evolution of sports dance costumes is the performance of sports dance culture and sports dance aesthetic development. In the process of sports dance show, the rhythmic, dynamic is the characteristics of sports dance. To a certain extent, Costumes and dance better display different dance style and aesthetic thought. Through the analysis of the sports dance types we can be found that modern and Latin dance as two main types, the different dance geographical, ethnic and cultural backgrounds make sports dance has more differences in the performance of the clothing. Except the outside sport style dance dress, dance clothing color is an important factor in sports dance aesthetic performance apparel. When the sports dance costume designers in the color selection, they on the one hand combined with style characteristics of sports dance, on the other hand the integration of ethnic and cultural connotation of sports dance to design the dress. The beauty of sports dance costumes make different sports dance with a more unique symbol, which create good conditions for the spread of culture and sports dance aesthetic shape in future.

\section{Conclusion}

In summary, the rituals as an important manifestation of the development of human civilization, ideological and cultural connotation of aesthetics explicit etiquette. In the ritual cultures, sports dance grace connotation feature sports culture. Thus, in the course of sports dance performances and study, reflect the cultural connotation of sports dance, the dancers need to double performances of sports artistic image and temperament. As one human thought, culture and art exchange way dance, Sport dance performance by the unique way to show their etiquette and culture, norms and lead the people's health and make a great significance in positive development of human physicals. Base on the recognition of sports dance ritual understanding cultural and aesthetic characteristics, it need to continue to strengthen dance practice and ritual embodied within compliance. In order to better promote the identity and cultural connotation of sports dance etiquette.

\section{References}

Di, J. Y. (2012). Value systems and content system construction of modern sports etiquette culture. Forefront, 2012(6).

Duan, G. M., \& Wang, D. M. (2008). Etiquette Training in Physical Dance Teaching. Ningbo University (Educational Science Edition), 2008(6). 
Tom, Z. (2007). Value and Teaching of Sports Dance in question should pay attention to. Science and Technology Information (academic studies), 2007(21).

Zhao, H. D., \& Li, J. (2012). Sport dance etiquette cultural analysis. The Big Stage, 2012(10).

\section{Copyrights}

Copyright for this article is retained by the author(s), with first publication rights granted to the journal.

This is an open-access article distributed under the terms and conditions of the Creative Commons Attribution license (http://creativecommons.org/licenses/by/3.0/). 